\title{
Comprehensive Overview of Iron Nutrition and Deficiency: Uptake, Transport and Metabolism in Legumes
}

\section{Sowbiya Muneer ${ }^{1 \dagger}$}

${ }^{1}$ School of Agricultural Innovations and Advanced Learning (VAIAL), Vellore Institute of Technology, Vellore, Tamil Nadu, India.

†Correspondence: sowbiya.muneer@vit.ac.in or sobiyakhan126@gmail.com

\begin{abstract}
Legumes are important sources of nitrogen and, therefore, the nitrogen fixing ability of the legumerhizobia symbiosis has great potential to improve crop yields or reduce nitrogen fertilizer use. Unfortunately, legumes face serious and increasing threats of both biotic and abiotic stresses among which Fe-deficiency has been increased from past years. Fe nutrient deficiency limits pulse production and nitrogen fixation by specifically affecting any one of the four phases of legume-rhizobium symbiosis. Although Fe in soil is often present in adequate quantities, it is mainly present in insoluble Fe-(III) precipitates, limiting its uptake and utilization. The present review has focused on the iron nutrition and deficiency and probable uptake, transport and metabolism in legumes.
\end{abstract}

Key words: Fe-uptake, Fe-transport, Fe-deficiency, Legumes 


\section{Introduction}

Pulses may be defined as the dried edible seeds of cultivated legumes. The nutritive properties of the pulses resemble in many respects those of the whole cereal grains; but there are important differences. First, the pulse protein is low in sulphur containing amino acids, but rich in lysine in which many cereals are deficient. A combination of pulses and cereal proteins may, therefore, have nutritive value as good as animal proteins [1-2]. Secondly, pulses as a class are good sources of the B group of vitamins except riboflavin. More important, the greater part of these vitamins present in the harvested seeds is actually consumed. There are no losses comparable with those that may arise in the milling and cooking of cereals. Pulses are therefore, an excellent preventive against beriberi. Thirdly, although pulses, like cereal grains, are devoid of vitamin C, large amount of ascorbic acid are found on germination. Sprouted pulses are, therefore, an important food which will protect against scurvy.

Mineral nutrient deficiencies may limit pulse production and nitrogen fixation by specifically affecting any one of the four phases of legume-Rhizobium symbiosis [3-5]. Apart from effects on host plant growth and metabolism, nutrient deficiencies may also limit survival and growth of Rhizobia in the soil and rhizosphere, nodule initiation and development, and nodule function. The iron is an essential element required by both the legume host and Rhizobium for range of physiological and biochemical processes of particular importance in iron nutrition of the symbiosis is the specific involvement of iron in several key proteins for nitrogen fixation e.g. Nitrogenase, leghemoglobin, ferredoxin, etc.

Fe deficiency is a major abiotic stress that affects many crop species, especially those grown in alkaline and calcareous soils [6-9]. Although these soils has abundant Fe but is not soluble thus often unavailable for plants inhibiting growth rates and crop yield [10]. Further, during Fe-deficient conditions plants may be susceptible to the stresses introduced into the environment by anthropogenic activities. Putting extensive threat to environment, the sources of such pollutants include industrial effluents and wastes, urban runoff, sewage treated plants, agricultural fungicide runoff, domestic garbage dumps, slow leaching rocks etc. Which are progressively affecting different ecosystems [11]. Fe is an essential element required by both legume and Rhizobium for a number of physiological and biochemical process of particular importance includes Fe nutrition of the symbiosis where there is specific association of Fe with several proteins for efficient nitrogen fixation etc. Being the fourth most abundant element in the lithosphere, Fe is generally present at high quantities in soil, but despite this, its bioavailability in aerobic and neutral $\mathrm{pH}$ environments is limited. In anaerobic soils, Fe is predominantly in the form of Fe (III), mainly as a constituent of oxyhydroxide polymers with extremely low solubility; in most cases this is insufficient to meet plant needs. An adequate supply of $\mathrm{Fe}$ is therefore required for the establishment and function of an effective symbiosis [12]. As with other mineral nutrients the symbiotic rhizobia are 
totally dependent upon the host plant for provision of supplies of Fe once root infection has occurred. As a component of many vital enzymes including the cytochrome of electron transport chain, it is required for wide range of biological function. In plants, $\mathrm{Fe}$ is involved in the synthesis of chloroplast structure and function $[5,13]$. The visual symptoms of inadequate Fe nutrition in higher plants are interveinal chlorosis of young leaves and stunted root growth. On the other hand, in water logged soils the concentration of soluble Fe may increase by several orders of magnitude because of low redox potentials. Under such conditions, Fe may be taken up in excess quantities and is potentially toxic as it promotes the formation of reactive oxygen based radicals, able to damage vital cellular constituents, notably membranes, by lipid peroxidation reaction.

\section{Iron uptake by legumes}

Iron is thought to be transported across the root plasma membrane as free $\mathrm{Fe}^{2+}$ via separate transporter acting downstream of the Fe (III) chelate reductase (Figure 1). The capacity of uptake and translocation of Fe is greatly enhanced upon Fe starvation [14-17]. Although changes in the uptake are correlated with changes in reductase activity. Young and Terry [18], showed that Fe deficiency induced an increase in both uptake rates and leaf concentration of $\mathrm{Fe}$ was supplied as $\mathrm{Fe}^{2+}$ via the nutrient solution, pointing to enhanced activity of plasma lemma $\mathrm{Fe}^{2+}$ transport protein. By contrast, Grusak et al., [19] found similar ratios of $\mathrm{Fe}^{2+}$ absorbed $\mathrm{Fe}$ (III) reduced in Fe replete and Fe deficient pea roots. They concluded that the activity of the root cell $\mathrm{Fe}^{2+}$ uptake system is not altered by Fe deficiency. This view was challenged by results of Fox et al., [20]. Using chelators buffered Fe labeled $\mathrm{Fe}^{2}+$ solutions the authors demonstrated and Fe deficiency induced increase in ferrous influx suggesting enhanced synthesis or activation of the transporter. Although this approach allows uncoupling of $\mathrm{Fe}^{2+}$ uptake from Fe (III) reduction, stimulatory effects of ferric reductase activity on the $\mathrm{Fe}^{2+}$ transporter cannot be excluded. It has further to be clarified whether the nascent $\mathrm{Fe}^{2+}$ generated by the reductase and the ferrous ions provided by the incubation medium enters the cell via the same route. Insights into the molecular basis of $\mathrm{Fe}^{2+}$ transport have been provided by Eide et al., [21]. Complementation of yeast mutant defective in Fe uptake with a cDNA library from Arabidopsis has led to the identification of a gene encoding a putative $\mathrm{Fe}^{2+}$ transporter that is expressed in Arabidopsis roots. The IRTI (Fe regulated transporter) gene was shown to confer Fe limited growth to yeast strain that has disruption in both the high affinity (FET3, ferrous Fe transport) and the low affinity (FET4) Fe transport system. The expression pattern of IRTI exclusively in Fe deficient plants no mRNA was detected under Fe replete conditions. Examination of amino acid sequence predicted from the cDNA insert suggests that $I R T 1$ is an integral protein comprising eight putative membrane spanning domains. Analysis of the functional properties of IARTI revealed hallmark properties of plant Fe uptake. These observations suggest that $I A R T 1$ is responsible for $\mathrm{Fe}^{2}+$ uptake from 
soil solution after reductase but not for the transport of Fe across the plasma membrane of leaf cells.

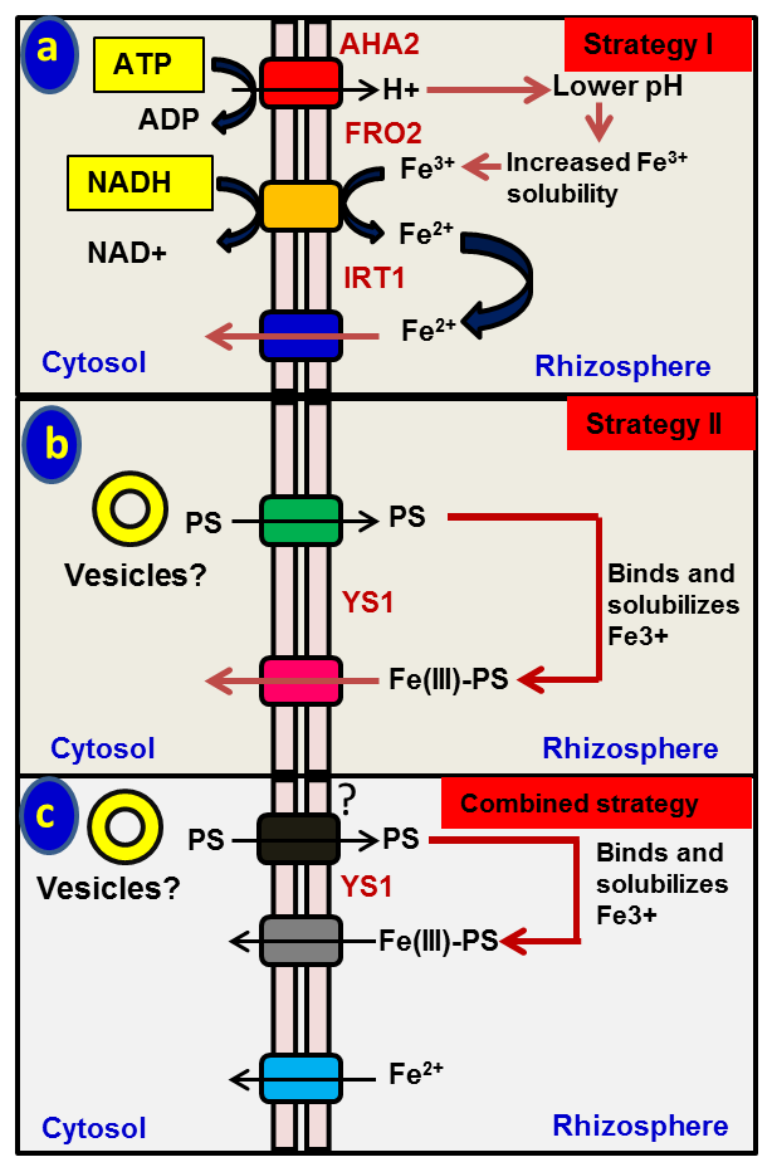

Fig 1: Diagrammatic representation of $\mathrm{Fe}-$ uptake and $\mathrm{Fe}^{2+}$ transport in plants

\section{Iron uptake by leaves and other aerial plant parts}

In the xylem iron is transported to the leaves in ferric form, chelated by citrate [22-23]. The exact mechanisms by which Fe enters leaf cells are only partially understood studies' using labelled Fe citrate and Fe citrate suggests that uptake of Fe by mesophyll cells depends on an obligatory reduction of ferric ions similar to the situation in roots [24-25]. It is not clear whether the ferric chelate reductase expressed in leaf cells is identical with that in root epidermis. The expression of Frohc, which encodes a putative Fe reductase, is enhanced in both roots and leaves of Arabidopsis, suggesting that this might well be the case, but as already mentioned, the role of Froh product is Fe uptake needs further clarification. Although some properties of leaf plasma membrane reductase reassembled those of redox system in roots. Reduction of $\mathrm{Fe}$ chelate in leaves is stimulated by light. The combination between these processes has been attributed to an increase in $\mathrm{NAD}(\mathrm{P}) \mathrm{H}: \mathrm{NAD}(\mathrm{P})+$ ratio through photosynthesis. Besides an increase in photosynthesis, light may play a significant role in Fe in leaves [26-27]. The importance of light is 
further indicated by the fact that, unlike in roots, the physiological effectiveness of Fe chelate during foliar nutrition is determined rather by photochemical features of chelate as compared to those of the carboxylic type [28], suggesting different mechanism underlying the reduction by the different organs.

Several reports underline the importance of the apoplasmic $\mathrm{pH}$ for mobility and availability of $\mathrm{Fe}$ in leaves which is strongly affected by bicarbonate in the soil and the form of $\mathrm{N}$ nutrition [28], chlorotic leaves often contain more Fe than green leaves (on the basis of dry weight), a phenomenon that has been referred to as "chlorosis paradox". A high $\mathrm{pH}$ of the leaf apoplast might affect the activity of $\mathrm{H}+\mathrm{ATpase}$ and /or reductase system on the plasma membrane, but this may not be only cause for impaired Fe uptake. As shown by Bienfait and Scheffers [29], photo-reduction of ferric carboxylates may cause the formation of inactive Fe species in leaves via photo reduction of citrate. A subsequent increase in $\mathrm{pH}$ results in the formation of large non diffusible polymer of ferric citrate [30]. This may be the cause of the restricted availability of Fe. Fe stress induced reduction activity has been observed in Lemaa gaba fronds [31], but no effect of the Fe nutritional status was observed in leaf disks of Sunflower [32], and Actinidia deliciora [33]. At the level of isolated plasma membrane, reduction activity was found to be 1.5 fold higher in Fe deficient sugar beet leaves [34-35], but no effect of Fe deficiency has been observed in plasma membrane from leaves of Vigna. It was observed that photosynthetic organelle were severely damaged under Fe-deficiency in Brassica napus [5] and Vigna radiata [36] thus reducing thylakoid proteins which in turn reduced photosynthetic activity.

\section{Iron sequestration}

The Fe present in antioxidant enzymes is obviously inactive for Fenton reactions, but this may be also true for other Fe proteins. There has been considerable controversy about whether certain Fe proteins from mammals, including hemoglobin, myoglobin, trans-ferritin and ferritin, can act as Fenton catalysis. It is now widely accepted that the Fe in those proteins in Fenton inactive but can become available for Fenton reaction if $\mathrm{Fe}$ is released from proteins following oxidative attack [37-40]. Soybean nodule leghemoglobin can release $\mathrm{Fe}$ when exposed to excess $\mathrm{H}_{2} \mathrm{O}_{2}$ but in this case a highly oxidized species not identical to $\mathrm{OH}$ radical is generated [41].

Ferritin is a protein especially suitable for Fe sequestration and storage, so playing a critical role in Fe homeostasis. Animal and plant ferritin are encoded by nuclear genes, having similar three dimensional structures and are induced by Fe overload [42]. However there are important differences between animal and plant ferritin. The gene of plant ferritin contains seven introns but that of animal ferritin contain only three introns. Animal ferritins are localized in the cytosol but plant ferritins are in the plastids. Control of animal ferritin synthesis by Fe occurs at the translational level and entails binding 
of $\mathrm{Fe}$ responsive proteins to $\mathrm{Fe}$ responsive elements located within the $5^{\prime}$ unsaturated region of the ferritin mRNA. Control of plant ferritin synthesis by Fe takes place at transcriptional level. The Fe released from ferritin is catalytic it will have to be incorporated rapidly in other proteins and chloroplasts will have to avoid any build up $\mathrm{H}_{2} \mathrm{O}_{2}$ which is formed continuously during photosynthesis. This may be good reason why chloroplasts have high levels of ascorbate peroxidase and other enzymes of ascorbate glutathione cycle. Similarly young legume nodules contain abundant ascorbate, protein and non-protein Fe and ferritin [43-44] because in nodules ferritin expression is developmentally regulated.

Fe deficiency has been reported worldwide in a number of agriculturally important crops, with deficiency usually occurring in alkaline soils and being attributed to the lowered availability of soil at high $\mathrm{pH}$ in calcareous soils [45-50]. Serious yield reductions and crop failures can result of Fe deficiency in several areas including Indonesia [51], Israel [52]), Taiwan [53] and Thailand [54]. The black calcareous soils of Thailand occupy over 500000 ha in the high lands of central and northern regions of country. Although these soils are considered quite fertile for most crops, Fe deficiency severely restricts growth and yield of peanut cultivars currently recommended for use in Thailand [54]. In some studies carried out on Fe requirements of the symbiosis [3,55], Fe has received considerable attention due to the dramatic effects observed when nodulated common bean is subjected to low iron availability. This element is frequently one of most limiting nutrients for plant growth in calcareous soils, and solution $\mathrm{Fe}$ does not cover more than $0.1-10 \%$ of plants Fe requirement.

$\mathrm{Fe}$ is known to be essential for many physiological and biochemical processes such as photosynthesis, respiration, DNA synthesis and N2 fixation. The legume rhizobia symbiosis is particularly sensitive to Fe deficiency [56]. The latter can limit root nodule bacterial survival and multiplication, as well as host plant growth, nodule initiation, development [57-58], and function [59]. In particular $\mathrm{Fe}$ is required for some key proteins involved in $\mathrm{N}_{2}$ fixation like nitrogenase, nitrogenase reductase and leghemoglobin [60-61], and nitrogen assimilation like glutamate reductase [62-63], and nitrate reductase [64].

Differences among species and genotypes in plant response to Fe deficiency have been reported for symbiotic legume, nodule initiation is less sensitive to Fe deficiency in Arachis hypogea than in Lupinus angustifolius [65]. Some genotypes of Lens culimaris and Cicer arietinum different in their ability to nodulate and to fix $\mathrm{N}_{2}$ on calcareous soil. Tolerant genotypes showed better uptake efficiency and a preferential allocation of this nutrient towards the nodules [65]. It is clear from these considerations that low nutrient availability can constrain plant growth in many environments of the world, especially the tropics where soils are extremely deficient in nutrients. Yet, the tendency in modern agriculture has 
been to select crop species for high soil fertility. This has resulted in the wide use of crops species for high soil fertility. This has resulted in the wide use of crop varieties that requires high doses of applied fertilizer in order varieties optimal plant growth and grain yield. Plant species growing in naturally fertile soil also tend to respond to nutrient supply in a manner similar to agricultural cultivars. Because of the high concentrations of plant available nutrients in fertilized or naturally fertile soils, root uptake rates are high. This is in sharp contrast to nutrient poor sites where root uptakes are usually low due to low or poor nutrient availability.

Plant uptake of nutrients from soil is more marked in the rhizosphere surrounding the root than outside this zone. Root exudation of various chemical molecules into the rhizosphere is largely dependent on the nutritional status of the plant, with some species exuding organic acid anions in response to $\mathrm{P}$ and $\mathrm{Fe}$ deficiency or phytosiderophores [7, 50, 57, 66-67] due to $\mathrm{Fe}$ and $\mathrm{Zn}$ deficiency. Consequently, the released compounds can cause some nutrient elements to be relatively more available for nutrient uptake by plants. The rate of exudation itself is increased by the presence of microbes in the rhizosphere, and promoted by the uptake and assimilation of certain nutrient elements. As a result, the composition of root exudates can be complex, and often ranges from mucilage, root border cells, extracellular enzymes, simple and complex sugars, phenols amino acids, vitamins, organic acids, nitrogenous macromolecules such as purines and nucleosides to inorganic or gaseous molecules such as HCO3-, $\mathrm{OH}-, \mathrm{H}+, \mathrm{CO}_{2}$ and $\mathrm{H}_{2}$ [68]. Many of these organic substrates excreted into the rhizosphere, particularly amino acids, organic acids, proteins, carbohydrates and vitamins, promote microbial biosynthesis of ethylene, a powerful plant signal controlling development that apart, these compounds all play a different role that ultimately affect nutrient acquisition by plants.

\section{Summary and conclusion remarks}

Alkaline soil forms a major area of crop production is mainly deficient in iron. Besides other crops, Fedeficiency also limits the pulse production. Iron is known to be essential for many physiological and biochemical processes such as photosynthesis, respiration, DNA synthesis and N2 fixation. The legume rhizobia symbiosis is particularly sensitive to Fe deficiency. Iron deficiency mainly affects the growth and development of plants and causes severe distress to various metabolic activities such as photosynthesis, respiration, DNA and RNA metabolism. It can limit root nodule bacterial survival and multiplication, as well as host plant growth, nodule initiation, development and function. Therefore, with advancement of scientific techniques, scientists are equipped with tools to understand plant metabolism and identify genes and proteins playing key roles during Fe deficiency which will greatly help in identification of stress-responsive protein and understand SNF (symbiotic nitrogen fixation) under stress. A novel strategy of proteins for the development of plants tolerant to abiotic stress, 
pathogens and disease resistant plants can be improved. It can enable us to understand the actual symbiotic relationship between host and pathogens. Different putative marker genes and proteins can be identified for the development of transgenic plants.

\section{References}

[1] Balasubramanium, S.; Borah, A.; Mahanta, C.L. Rheological and nutritional properties of legumes incorporated corn extrudates. Inter Food Res J. 2012, 19(3), 971-975.

[2] Teixeira, D.C.; Farias, D.F.; Carvalho, A.F.U.; Arantes, M.R.; Oliveira, J.T.A.; Sousa, D.O.B.; Pereira, M.L.; Oliveira, H.D.; Andrade-Neto, M.; Vasconcelos, I.M. Chemical composition, nutritive value, and toxicological evaluation of Bauchinia Cheilantha seeds: A legume from semiarid region widely used in folk medicine. Biomed Res Inter, 2013, Article ID 578781, 7 pages

[3] Krouma, A.; Abdelly, C. Importance of iron use efficiency in common bean (Phaseolus vulgaris L.) for iron chlorosis resistance. J Plant Nutr. Soil Sci. 2003, 4, 525-528.

[4] Muneer, S.; Kim, T.H.; Qureshi, M.I. Fe modulates Cd-induced oxidative stress and the expression of stress response proteins in the nodules of Vigna radiata. Plant Grow Regul. 2012, 68, 421-433.

[5] Muneer, S.; Lee, B.R.; Kim, K.Y.; Park, S.H.; Zhang, Q.; Kim, T.H. Involvement of sulphur nutrition in modulating iron deficiency responses in photosynthetic organelles of oilseed rape (Brassica napus L.). Photosynth Res. 2014, 119, 319-329.

[6] Lindsay, W.L.; Schwab, A.P. The chemistry of Iron in soils and its availability to plants $J$ of plant Nutr. 1982, 5, 821-840.

[7] Meda, A.R.; Scheuermann, E.B.; Prechsl, U.E.; Erenoglu, B.; Schaaf, G.; Hayen, H.; Weber, G.; Wiren, N.V. Iron Acquisition by Phytosiderophores Contributes to Cadmium Tolerance. Plant Physiol 2007, 143, 1761-1773.

[8] Theil, E.C. Iron homeostasis and nutritional iron deficiency. J Nutr. 2011, 141, 724S-728S.

[9] Santos, C.S.; Silva, A.I.; Serrao, I.; Carvalho, A.L.; Vasconcelos, M.W. Transcriptomic analysis of iron deficiency related genes in the legumes. Food Res. Int. 2013, 54, 1162-1171.

[10] Chen, Y.; Bark. Iron nutrition of plants in calcareous soils adv. Agronomy 1982, 35, 217-240.

[11] Macfarlance, G.R.; Burchett, M.D. Photosynthetic pigments and peroxide activity as indicators of heavy metal stress in the grey mangrove, ancient marina (Forste). Virch Mar Point Bull. 2001, 42, $233-40$.

[12] Geetha, S.J.; Joshi, S.J. Engineering rhizobial bioinoculants: A strategy to improve iron nutrition. The Scientific world J, 2013, Article ID 315890, 15 pages

[13] Abadia, J.; Leaf response of Fe deficiency: a review. J of Plant Nutr. 1992, 15, 1699-1713.

[14] Yi, Y.; Guerinot, M.L. Genetic evidence that induction of root Fe (III) chelate reductase activity is necessary for iron uptake under iron deficiency. Plant J. 1996, 10, 835-844.

[15] Astolfi, S.; Zuchi, S.; Neumann, G.; Cesco, S.; Sanita di Toppi, L.; Pinton, R. Response of barley plants to Fe deficiency and $\mathrm{Cd}$ contamination as affected by $\mathrm{S}$ starvation. $J$ Exp. Bot. 2011, 63, 1241-1250.

[16] Waters, B.M.; Mclnturf, S.A.; Stein, R.J. Rosstte iron deficiency transcript and microRNA profiling reveals links between copper and iron homeostasis in Arabidopsis thaliana. J Exp. Bot. 2012, 16, 5903-5918. 
[17] Kobayashi, T.; Nagasaka, S.; Senoura, T.; Itai, R.N.; Nakanishi, H.; Nishizawa, N.K. Iron-binding haemerythrin RING ubiquitin ligases regulate plant iron responses and accumulation. Nature Comm. 2013, 4, 2792-3792.

[18] Young, T.F.; Terry, N. Transport of iron into leaves following iron resupply to iron-stressed sugar beet plants. $J$ of Plant Nutr. 1982, 5, 1273-1283.

[19] Grusak, M.A.; Welch, R.M.; Kochian, L.V. Does iron deficiency in Pisum sativum enhances the activity of the root plasmalemma iron transport proteins? Plant Physiol. 1990a, 94, 1353-1357.

[20] Fox, T.C.; Shaff, J.E.; Grusak, M.A.; Norvell, M.A.; Chen, Y.; Chaney, R.L.; Kochian, L.V. Direct measurement of ${ }^{59}$ labelled $\mathrm{Fe}^{2+}$ influx in roots of Pisum sativum using a chelator buffer system to control free $\mathrm{Fe}^{2+}$ in solution. Plant Physiol. 1996, 111, 93-100.

[21] Eide, D.; Broderius, M.; Feit, J.; Guerinot, M.L. A novel iron-regulated metal transport from plants identified by functional expression in yeast. Proc Nat Acad of Sci USA, 1996, 93, 5624-5628.

[22] Tiffin, L.O. Ion translocation. I. Plant culture, exudate sampling, iron-citrate analysis. Plant Physiol. 1996, 45, 280-283.

[23] White, P.F.; Robson, A.D. Rhizospheric acidification and Fe3+ reduction in lupins and peas: iron deficiency in lupins is not due to a poor ability to reduce $\mathrm{Fe}^{3+}$. Plant and Soil 1989, 119, 163-175.

[24] Bruggenmann, W.; Mass-Kantel, K.; Moog, P.R. Iron uptake by mesophyll cells: the role of the plasma membrane-bound ferric-chelate reductase. Planta 1993, 190, 151-155.

[25] Lo'pez-Millan, A.F.; Morales, F.; Abadia, A.; Abadia, J. Effects of iron deficiency on the composition of leaf apoplastic fluid and xylem sap in sugar beet. Implications for iron and carbon transport. Plant Physiol. 2000, 124, 873-884.

[26] Brown, J.C.; Foy, C.D.; Bennett, J.H.; Christiansen, M.N. Two light sources differentially affected ferric iron reduction and growth of cotton. Plant Physiol. 1979, 63, 692-695.

[27] Pushnik, J.C.; Miller, G.W.; Jolly, V.D.; Brown, J.C.; Davis, T.D.; Barnes, A.M. Influence of ultraviolet (UV)-blue light radiation on the growth of cotton. II. Photosynthesis, leaf, anatomy, and iron reduction. $J$ of Plant Nutr. 1987, 10, 2283-2297.

[28] Mengel, K. Iron availability in plants tissues-iron chlorosis on calcareous soils. In: Abadia J, ed. Iron nutrition in soils and plants. Dordrecht, The Netherlands: Kluwer Academic Publishers, 1995, 389-397.

[29] Bienfait, H.F.; Scheffers, M.R. Some properties of ferric chelate relevant to the iron nutrition of plants. Plant and Soil 1992, 143, 141-144.

[30] Spiro, T.G.; Bates, B.; Saltman, P. The hydrolytic polymerization of ferric citrate. II. The influence of excess citrate. $J$ of American Chem Soci. 1967, 89, 5559-5562.

[31] Lass, B.; Thiel, G.; Ullirch-Eberius, C.I. Electron transport across the plasmalemma of Lemma gibba. Planta 1986, 169, 251-259.

[32] De la Guardia, M.D.; Alcantara, E. Ferric chelate reduction by sunflower (Helianthus annus L.) leaves: influence of light, oxygen, iron deficiency and leaf age. J of Exp. Bot. 1996, 47, 669-675.

[33] Rombola, A.D.; Bruggmen, W.; Tagliavini, M.; Moog, P.R. Iron deficiency in kiwifruit (Actinidia deliciosa): response of roots and leaves. Abstract p66, 9th international symposium on iron nutrition and interactions in plants 1997 Stuttgart, Germany.

[34] Gonzalez-Vallejo, E.B.; Abadia, A.; Gonzalez-Reyes, J.A.; Abadia, J. Characterization of Fe (III)chelate reductase activities of plasma membrane preparations isolated from leaves of iron-sufficient and iron-deficient sugar beet (Beta vulgaris L.) Abstract p55, 9th international symposium on iron and interactions in plants, 1997, Stuttgart, Germany. 
[35] Robinson, N.J.; Sadjuga, M.R.; Groom, Q.J. The Froh gene family from Arabidopsis thaliana: Putative iron-chelate reductase. Plant and Soil 1997, 196, 245-248.

[36] Muneer, S.; Ahmad, J.; Qureshi, M.I Involvement of Fe nutrition in modulating oxidative stress and the expression of stress response proteins in leaves of Vigna radiata L. Aust J Crop Sci. 2013, 7(9), 1333-1342

[37] Aust, S.D. Morehouse, L.A.; Thomas, C.E. Role of metals in oxygen radical reactions. Free Rad Biol Med. 1985, 1, 3-25.

[38] Gutteridge, J.M.C. Iron promoters of the Fenton reaction and lipid peroxidation can be released from hemoglobin by peroxides. FEBS Lett. 1986, 201, 291-295.

[39] Halliwell, B.; Gutteridge, J.M.C. Role of free radicals and catalytic metal ions in human disease: an overview. Methods Enzymol. 1990, 186, 1-85.

[40] Vigani, G. Discovering the role of mitochondria in the iron deficiency-induced metabolic response of plants. $J$ Plant Physiol. 2011, 1, 1-11.

[41] Puppo, A.; Halliwell. B. On the reaction of plant ferredoxins with hydrogen peroxide. What reactive oxidants are generated? Phytochemistry 1989, 28, 3265-3270.

[42] Briat, J.F.; Laboure, A.M.; Laulhere, J.P.; Lescure, A.M.; Lobre Âaux, S.; Pesey, H.; Proudhon, D.; Wuytswinkel, O. Molecular and cellular biology of plant ferritins, in Abadia J. (ed.) Iron Nutrition in soils and plants. The Netherlands, Kluwer Academic Publishers, 1995, pp. 265-276.

[43] Becana, M.; Klucas, R.V. Transition metals in legume root nodules: iron-dependent free radical production increases during nodule senescence. Proc. Natl. Acad. Sci. USA. 1992, 89, 8958-8962.

[44] Dalton, D.A. Antioxidant defenses of plants and fungi. In Oxidative Stress and Antioxidant Defenses in Biology. Ed. S Ahmad. 1995, pp 298-355. Chapman and Hall, New York.

[45] Ranieri, A.; Castagna, A.; Balden, B.; Soldatni, G.F. Iron deficiency differently affects peroxidase isoforms in sun flower. $J$ Exp. Bot. 2001, 52(354), 25-35.

[46] Abadia, J.; Vazquez, S.; Rellan-Alvarez, R.; El-Jendoubi, R.; Abadia, A.; Alvarez-Fernandez, A. Towards a knowledge-based co-reaction of iron chlorosis. Plant Physiol. Biochem. 2011, 49, 471482.

[47] Vose, P.B. Iron nutrition in plants: a world overview. $J$ of Plant Nutr. 1982, 5, 233-249.

[48] Romheld, V.; Marschner, H. Mobilization of iron in the rhizosphere of different plant species. In: Advances in plant Nutrition (Ed. By B. Tinker and A. Lauchli), 1986, Vol. 2, pp. 155-204. CSIRO, Melbourne.

[49] Zuchi, S.; Cesco, S.; Varanini, Z.; Pinton, R.; Astolfi, S. Sulphur deprivation limits Fe-deficiency responses in tomato plants. Planta 2009, 230, 85-94.

[50] Astolfi, S.; Zuchi, S.; Hubberten, H.M.; Pinton, R.; Hoefgen, R. Supply of sulphur to S-deficient young barley seedlings restore their capability to cope with iron shortage. J Exp. Bot. 2010, 61(3), 799-806.

[51] Field, S.; Vameli, J. Food legumes for Calcareous soils of Timor. ACIAR workshop on food legumes improvement for Asian farming systems, 1987, Khon Kaen, Thailand.

[52] Hartzook, A. The problem of iron deficiency in peanuts (Arachis hypogea L.) on the basis and calcareous soils in Israel. J of Plant Nutr. 1982, 5, 923-926.

[53] Lee, D.Y.; Lin, C.H.; Huang, S.P.; Houng, K.N. Effects of sulfur application to calcareous soils in Hualien area on the yields of peanuts. Soils and fertilizer in Taiwan 1983, 12, 35-43.

[54] Ratanart, S.; Parkpian, P.; Phetchawee, S. Iron deficiency in peanut on black calcareous soils. In: 
Proceedings of the international symposium on food legumes improvement for Asian farming systems, 1-5 sept. 1986. Khon Kaen, Thailand.

[55] Mortvedt, J.J. Correcting iron deficiency in annual and perennial plants: present technologies and future prospects. Plant and Soil 1991, 130, 273-279.

[56] Tang, C.; Robson, A.D.; Dilworth, M.J. The role of iron in nodulation and nitrogen fixation in Lupinus angustifolius L. New Phytol. 1990, 114, 173-182.

[57] O'Hara, G.W.; Dilworth, M.J.; Boonkerd, N.; Parkpian, P. Iron-deficiency specifically limits nodule development in peanut inoculated with Bradyrhizobium sp. New Phytol. 1988, 108, 51-57.

[58] Ragland, M.; Theil, E.C. Ferritin (mRNA, protein) and iron concentrations during soybean nodule development. Plant Mol. Biol. 1993, 21, 555-560.

[59] Krouma, A.; Drevon, J.J.; Abdelly, C. Genotypic variation of $\mathrm{N}_{2}$ fixing common bean (Phaseolus vulgaris L.) in response to iron deficiency. J Plant Physiol. 2006, 163, 1094-1100.

[60] Moral, R.; Palacios, G.; Gómez, I.; Navarro-Pedreno, J.; Mataix, J. Distribution and accumulation of heavy metals $(\mathrm{Cd}, \mathrm{Ni}$ and $\mathrm{Cr}$ ) in tomato plant. Fresenius Environ Bull. 1994, 3, 395-399.

[61] Qureshi, M.I.; Muneer, S.; Bashir, H.; Ahmad, J.; Iqbal, M.I. Nodule physiology and proteomics of stressed legumes. Adv. Bot Res. 2010, 35, 1-47.

[62] Vanoni, M.A.; Curti, B. Structure-function studies on the iron-sulfur flavoenzymes glutamate synthase: an unexpectedly complex self-regulated enzyme. Arch Biochem. Biophy. 2005, 433, $193-$ 211.

[63] Qureshi, M.I.; Qadir, S.; Zolla, L. Proteomic based dissection of stress responsive path ways in plants. J Plant Physiol. 2007, 164, 1239-1260.

[64] Clemens, S.; Palmgreen, M.G.; Kramer, U. A long way ahead: understanding and engineering plant metal accumulation. Trends Plant Sci. 2002, 7, 309-315.

[65] Tang, C.; Robson, A.D.; Dilworth, M.J.; Kuo, J. Microscopic evidence on how iron deficiency limits nodule initiation in Lupinus angustifolius L. New Phytol. 1992, 121, 457-67.

[66] Kawai, S.; Kamei, S.; Matsuda, Y.; Ando, R.; Kondo, S.; Ishizawa, A.; Alam, S. Concentrations of iron phytosiderophores in xylem sap of iron deficient barley plants. Soil Sci and Plant Nutr. 2012, 77(2), 265-272.

[67] Itai, R.N.; Ogo, Y.; Kobayashi, T.; Nakanishi, H.; Nishizawa, N.K. Rice genes involved in phytosiderophore biosynthesis are synchronously regulated during early stages of iron deficiency in roots. Rice 2013, 6-16.

[68] Rovira, A.D. Plant root exudates. Bot Rev. 1969, 35, 35-57. 